\title{
An Emergency Supplies Scheduling for Chemical Industry Park: Based on Super-Network Theory
}

\section{Yu Yuan ( $\nabla$ yuanyu24@sjtu.edu.cn )}

Shanghai Jiao Tong University

Fei Wang

Sun Yat-Sen University

\section{Research Article}

Keywords: super network, chemical industry parks, relief scheduling, regional collaboration

Posted Date: July 26th, 2021

DOI: https://doi.org/10.21203/rs.3.rs-600908/v1

License: (c) (1) This work is licensed under a Creative Commons Attribution 4.0 International License. Read Full License

Version of Record: A version of this preprint was published at Environmental Science and Pollution Research on January 31st, 2022. See the published version at https://doi.org/10.1007/s11356-021$18182-y$. 
An Emergency Supplies Scheduling for Chemical Industry Park: Based on Super-Network

Theory

Yu Yuan ${ }^{1}$, Fei Wang ${ }^{2}$

1. China Institute for Urban Governance, Shanghai Jiao Tong University, Shanghai, PR China

2. International School of Business and Finance, Sun Yat-sen University, Zhuhai, PR China;

Correspondence: Yu Yuan, China Institute for Urban Governance, Shanghai Jiao Tong

University, Shanghai, China. Tel: +86 18297942586; E-mail: yuanyu24@sjtu.edu.cn 


\title{
An Emergency Supplies Scheduling for Chemical Industry Park: Based on Super-Network
}

\section{Theory}

\begin{abstract}
In a concentrated area of Chemical Industry Parks (CIPs), emergency relief efficiency is not only affected by the rescue capability of themselves, but also their relationships with other CIPs. Academic literature suggests the use of multiple networks such as transport network and information network, in the emergency process after unexpected events, but rarely integrates them ideally in practice. This paper utilizes the super network theory to propose a regional emergency scheduling model to bridge the logistic and relation among CIPs. The proposed super-network model is composed of resources flow network and relationship network that fill a gap of only considering emergency logistic supply chain. Therefore, the main problem is to how coordinate all the disaster relief actors including primary relief centers (PRC) local relief centers (LRC) and CIPs. The proposed model provides an optional answer regarding the optimal configuration (one-stage or two-stage), the optimal type, number and transportation direction of resources. We turn the optimization problem into a variational inequality problem and develop a modified projection algorithm to solve the problem and compare the performance under several disaster scenarios. The practicability of the model is proved by the result of the numerical example given.
\end{abstract}

Keywords: super network; chemical industry parks; relief scheduling; regional collaboration 


\section{Introduction}

The emergence of chemical industry parks (CIPs) is the embodiment of development of industrialization processes, with the centralized layout of CIPs, the possibility of major contingency increases. There are numerous concealed threats in CIPs because of the wide varieties of hazards and pollution sources that are intensively distributed in such areas. Once an accident occurs, it is easy to produce domino effect and secondary disasters if it is not disposed timely. For example, one factory's fire at Tianjin Port in China on August 12, 2015 triggered two shocked explosions that not only caused serious casualties and economic losses but also resulted in an extremely negative social impact. Natural hazards, such as earthquakes, floods, and geomagnetic storms, are also major latencies in CIPs. All hidden dangers are considered low probability but high-consequence events with significant social impact (Francesca \& Matjaž, 2020; Reniers et al., 2005), and thus, providing quick response and improving emergency dispatching capability for the aftermath of an incident in CIPs presents considerable challenges (Rogers et al., 1990; Du et al., 2020).

Since unpredictability and destructiveness of chemical accidents, emergency outbroke in CIPs destroys and sprawls within an area, and as a result, some specific resources may overwhelm capability of single factory or park due to a sudden spike in demand for relief resources. Emergency relief cooperation has been proven to be an effective road given the complexity of a relief network, which involves materials, traffic, and information, among others (Groothedde et al., 2005). The cluster of CIPs magnify the possibility of risk but in turn, it also provides a geographical basis for the construction of a regional emergency linkage mechanism.

Super network theory is one of the most appropriate methods used to address the multi-network problem (Nagurney et al., 2007). According to Nagurney (2007), super network is a network with higher dimension than the average network, the properties of other dimensions can be mapped onto the benchmark attribute network structure under the premise of selecting the optimal resource allocation. It is propitious to the coordination of a regional emergency and the cooperation of multiple agents to extract representative networks from complex rescue networks. From the operational perspective, we need to determine which of the available agents should be considered in the response according to their capacity, category, proximity and relation to the emergency site(s). Considering the multidimensionality involved in the actual rescue process, therefore, two types of sub-networks, namely, the relationship network and resources flow network, are designed using the proposed super network theory. The resources flow network, which can be constructed by agents and transportation paths, is common sense in emergency logistic study. The relationship network, however, the line is just an insubstantial affiliation between two relief agents. In fact, this affiliation enhanced as geographic distance decreased, and it also strengthened as similarity of industry mode, for 
example, the relationship between biological chemistry and petrochemical chemistry weakened notably than that between two petrochemical industries. In comparison with single physical network, decision to deploy reginal resources relied on the two networks is more realistic and reliable.

Regardless the rich literature on emergency response problems, demand points, relief suppliers, and distribution centers usually defined in general relief scheduling problems (Sheu 2007), and the locations and capabilities of resource providers are key components in managing response efforts after a disaster (Fiedrich et al., 2000; Tsai et al., 2002). However, in concentrated areas of CIPs, suppliers are not predetermined and all agents within zones deployed their own relief resources, they are potentially not only the ones that demand for relief resources but also the supplies providers or the transfer station. This study aims to determine the optimal allocation with limited emergency resources immediately, and an alternative two-stage relief system is constructed to determine small or large scheduling portfolios for different disaster scenarios.

The main difference between the focus of this study and those considered for emergency logistic scheduling in previous literature is that this method involves a super network, which is combined by the relation network and resource flow network, thereby considering resource diversity and agents heterogeneity. It is helps to establish a regional coordination mechanism to make resource dispatching in line with the actual situation. The remaining parts of this study are organized as follows. Section 2 presents the literature review on emergency scheduling models. Section 3 formulates the problem and provides details of our modeling technique, and section 4 explains the methodology developed to solve the super network problem. Section 5 demonstrates the experimental design used to test the model and discusses the computational results, and finally the conclusions and suggests possible extensions of the current work are presented in section 6.

\section{Literature review}

With the development of the chemical industry in China, enormous hazardous materials (i.e., toxic, flammable, or explosive substances) are inevitably involved in manufacturing processes; these materials can potentially lead to major environmental accidents, such as chemical leakage, fire, explosion, or toxic material proliferation, causing catastrophic effects and leading to heavy casualties and tremendous property losses (Georgiadou et al., 2010; Zhou \& Liu, 2012; Fan, 2014). Research on rescue scheduling problem is abundant, and many decision models have been developed to solve various rescue scheduling problems, including the ones in the context of chemical accidents (Baser \& Behnam, 2020; Duan et al., 2015; Liu et al., 2017), as well as the ones for large-scale natural hazards (Wex et al., 2014), which may trigger "domino accident" - means that one disaster leads to another (Khan et al., 2001). A new methodology based on system management and operational research was proposed by 
Kourniotis et al., (2001), this method aims to improve effective chemical emergency management. Protective actions for decision-making in nuclear or chemical plants have been extensively recorded in the literature (Rogers et al., 1990; Hedemann-Jensen, 2004; Du et al., 2020), but few studied concentrated areas with chemical risks, such as CIPs clusters. Meanwhile, emergency scheduling coordination for chemical contingency of CIPs is also a complicated task due to the diversity of pollution conditions (Liu et al., 2017). In practical terms, emergency resources scheduling is difficult to assess accurately with qualitative and quantitative information because of inherent and highly uncertainty and imprecision (Zhang et al., 2012). Therefore, improving existing scheduling optimization model to accommodate the special characteristic of CIPs has more practical significance in urban areas.

Emergency cross-regional cooperation had been verified as superior way to response to regional large-scale emergency (Fu and Piplani 2004; Chen et al., 2016). Green and Kolesar (2004) pointed out that regional coordination is an important development direction in the future. Evidently, Groothedde et al., (2005) demonstrated that interoperable networks of cities can effectively reduce logistics costs while maintaining service levels. Kapucu et al., (2010) suggested that the investment in community capacity at the local and state level should be increased and the cooperation among local, state and federal agencies of the resources should be considered. The literature addressed various aspects of relief agent coordination are elicited attention on humanitarian relief (Hackl and Pruckner 2006; Balcik et al., 2010). Humanitarian relief environments engage many sector companies, each of which may have different interests, capacity, and logistics expertise. Typically, no single actor has sufficient resources to respond effectively to a major disaster. It is a similar context that discussed in this paper, so the multi-network is appropriately applied in the model constructing.

Logistics network, as an essential conveyor of tangible materials between suppliers and receivers, is played a significant role in the emergency relief process and has been widely discussed in most literature (Chang et al., 2007; Feng et al.; 2020). In addition to the flow of resources, transportation and information, certain relationships exist among different agents in a rescue network. These relationships include natural relationships (e.g., geographical distance, grade of connecting roads) and social relationship (e.g., similarity of stored resources, cooperation and trade).

Most existing studies recognize that super network theory is suitable for describing and representing different attributes (Yamada and Imai 2011; Zhao et al., 2017; Zhu and Cao 2012). Nagurney et al., (2002), who first applied the concept of super networks to a supply chain. In subsequent studies (Nagurney et al., 2007), they constructed a super network model to analyze interactions and relationships between the global supply chain and international financial networks. Cruz and Liu (2011) analyzed the effects of social relationship levels on a multi-stage supply chain network, in which multiple decision makers are associated at 
different tiers. Although there is little literature of super network on relief study, the super network method has been determined to be favorable in solving the problem of cross-regional emergency coordination.

Another challenge is that large-scale emergency rescue dispatching problem unavoidably involves huge sets of geographical data, implying that model's efficient solving is difficult. At present, the approaches proposed for solving large-scale scheduling problem are generally exact approaches, such as linear, nonlinear or other mathematical programming methods $(\mathrm{Du}$ et al., 2020; Horner and Downs 2010; Maliszewski et al., 2012; Bell et al., 2011). For solving super network model, it is variational inequality that is generally used.

\section{Materials and methods}

\subsection{Problem description}

In keeping with standard views about the necessity of emergency cooperation, this section presents the formal modeling of the dispatching problem on cross-regional emergency of CIPs based on the conceptual description. Ultimately, this paper aims to answer the following questions.

(1) How are the interaction effects of complex networks presented and how does network interaction affect scheduling decision?

(2) How rescue points are selected under various cases based on the existing distribution of CIPs and other relief centers (RCs)?

(3) How can the total emergency operating cost be minimized to meet the demand?

The intention of the model is finding the optimal classified relief resource scheduling program that can minimize total cost amid the swarm of networks. To solve these questions and transform a complex realistic problem into the super network model, the nature of a super network should be first understood. As mentioned before, super network theory has been applied to express knowledge networks, logistics networks, and emergency management (Nagurney \& Dong, 2002; Zhao et al., 2017; Zhu \& Cao, 2012). Compared with other research tools, the advantage of applying super network theory to solve the problem of cross-regional emergency resource scheduling is that the properties of other dimensions can be mapped onto the benchmark attribute network structure under the premise of selecting the optimal resource allocation to achieve the goal of overall optimization.

Logistics network, the fundamental and widely studied one because of its physical attribute, become the first sub-network inevitably to build a super network. This way, the basic nodes, lines and spatial structure are constructed. The question that comes with is what affects the resources dispatching between two nodes of logistics network. Notably, there are still many factors include but not limited spatial accessibility of from origin to destination, demand for resources of each crisis locations, available supplies of retrieval depots and so on. So a "relationship network" is proposed and alliance with logistics network to develop a super 
network nested structure. The relationship network means a network composed of nodes and their relations that specifically embodied as spatial distance and similarity of reserved resources in this model.

The two networks draw from complex reality and form a super network structure, as shown in Fig. 1, where the solid line in the resource flow network shows the amount of delivery resources between two emergency agents and the solid line in the relationship network shows the degree of social relationship between two emergency agents. The points linked by one dotted line indicates that they are the same one but means different in the two networks.

<Insert Fig.1 here>

Without losing generality, primary relief centers (PRCs), local relief centers (LRCs), and CIPs coexist in a large region, and each agent preserves relief resources stocks and finds a balance between reducing cost and addressing potential damages. All agents will cooperate to deal with an emergency situation in the spirit of humanitarianism. Every CIP may suffer an unexpected disaster. Once a contingency outbreak at a CIP, it becomes the demand point in the network, whereas other emergency agents become rescue points or transfer points, depending on their relationship to the demand point. As shown in Fig. 2, the emergency relief network of a certain region consists of rescue points, transfer points, and demand points.

The current work solves the dispatching and cooperation problem when a major accident occurred at some CIPs in reginal. Similar to the sequence of events for standard emergency medical system calls discussed by Fitzsimmons (1973), Fig. 2 depicts the process of a two-stage supply chain network for CIPs. The first stage is related to the processing of LRCs, unaffected CIPs play the part of rescue points and provide relief resources to demand points, and the second stage adds two routines, the establishment of PRCs and other unaffected CIPs as rescue points directly to demand points or indirectly deliver resources to transfer points. For small-scale disasters, the first stage of relief system starts with directly transportation to affected CIPs, the suppliers are selected from LRCs and unaffected CIPs. If a calamity is particularly serious, the rescue cover of first stage may be insufficient to satisfy the demands and to support all emergency logistics operation. At this point, the second stage relief system is implemented, more PRCs, LRCs, and unaffected CIPs are involved in the emergency relief network considering the relationship loosely.

Taking into account the diversity of materials, each demand point $k$ requires two types of resources in this context: professional relief supplies (e.g., firefighting equipment and life-saving/defending equipment) and daily necessities (e.g., drinking water, food). There is a little difference of this situation from the other emergency relief scheduling problem, all points in the region have resources stocks including CIPs themselves, such that they may become rescue points. Particularly, the reserved resources of a park can meet a part of needs under emergency situation. their resources will encounter a certain degree of damage due to 
the destructions caused by disaster (Jia et al., 2007; Paul and Batta 2008). This situation can be expressed by introducing a resource retention factor $\rho$.

\section{<Insert Fig.2 here>}

\subsection{Assumptions}

The basic assumptions of this work are as follows.

(1) Each affected CIP receives its relief resources from other agents.

(2) The total quantity of resources reserved in emergency agents within a region can be sufficient for any large-scale disaster.

(3) LRCs can be selected as rescue or transfer points within a region, but PRCs and unaffected CIPs can only be candidate sets for rescue points.

(4) Relief supplies are predictable once a CIP suffers from an accident.

(5) The locations of PRCs, LRCs, and CIPs are fixed, and the reserved resources are known.

(6) A super network is a perfect network where every node pair is accessible but road capacity is limited.

(7) The objective is nonlinear, but the association with resource flow and the relationship among emergency agents are quadratic.

\subsection{Model formulation}

In a given large region, all emergency agents $N$ include PRCs (denoted as $P$ ), LRCs (denoted as $L$ ), and CIPs (denoted as $U$ ). If an unexpected event occurs and some CIPs $K$ are affected, then $k, k \in K$ for each CIP. If the first stage is triggered, i.e., $\delta_{1}=1$, then supplies may be received from emergency subjects in the first stage $J$; for $\forall a \in C_{U} K$, if $r_{a k} \geq \tau_{1}$, then $a \in J$. Moreover, if $l \in L$, then $l \in J$ for every LRC. We can set another relaxed threshold $\tau_{2}\left(\tau_{2}>\tau_{1}\right)$ to allow more points to provide supplies that can fit different scenarios; that is, for $\forall a \in C_{U} K$, if $r_{a k} \geq \tau_{2}$, then $a \in J$. Furthermore, if demand exceeds the capacity of the selected rescue depot; that is, if the second stage is triggered, i.e., $\delta_{2}=1$, then each demand point may receive resources from subjects in the second stage $I$. For $\forall b \in C_{U}(K \cup J)$, if $r_{b k} \geq \tau_{3}$ or $r_{b j} \geq \tau_{4}$ for any $k \in K, j \in J, \tau_{4}>\tau_{3}>\tau_{2}$, then $b \in I$. To be rigorous, for $\forall r_{a b}, \tau_{1} \leq r_{a b} \leq \tau_{4}$. PRCs will participate in the relief work in any large-scale disaster considering humanitarian reasons. Let $P \subseteq I$. Then, all emergency subjects may be selected, and the process is shown in Fig. 3. 
At this point, the problem is to allocate diverse relief supplies to demand depots from other agents except the affected CIPs along different routes in support of emergency operations to minimize total delay. We summarize the sets, indices, and parameters used in our problem as follows.

Model sets/indices/parameters

$N$ All emergency subjects within in region

$U$ All CIPs within in region

$P \quad$ All primary relief centers within region

$L \quad$ All local relief centers within region

I $I \subset C_{U}(K \cup J) \cup P$, the set of rescue points involved in second stage

\section{$K$ The set of demand points}

$H$ The set of resources types

$i \quad$ The second-stage rescue point which delivers supplies to demand points indirectly (PRC and unaffected CIPs) and unaffected CIPs)

$k \quad$ Demand point (affected CIPs)

$h \quad$ Types of resources

$r_{a b}$ The degree of relationship between $a$ and $b$

$q_{a b h}$ Transport of resources of type $h$ between $a$ and $b$

$g_{a b}$ The general transportation costs between $a$ and $b$

$u_{a b}$ The maximum capacity of the road from $a$ to $b$

$A_{a h}$ Resources of type $h$ reserved in the $a$

$d_{k h}$ Resources demand of type $h$ in the $\mathrm{k}$

$\rho$ The retention coefficient of the resources in the disaster scenario

$d_{a b}$ The actual distance between point $a$ and $b$

$s_{a b}$ The similarity of reserve resources between point $a$ and $b$ 
$\alpha$ The weight value of the distance

Besides, we define two sets of binary variables as a trigger to select the relief system as follows: expression that involves the aforementioned two sub-networks, which is denoted as follows:

$$
\min \sum_{j} \sum_{k} \sum_{h} g_{j k h}\left(q_{j k h}, r_{j k}\right)
$$

This is subject to the following sets of constraints:

$$
q_{j k h} \geq 0, \quad A_{j h} \geq 0, A_{k h} \geq 0, \quad \forall j \in J, \forall k \in K
$$

In this model, the objective function (1) minimizes the total cost of the first stage across rescue points $j$ to demand points $k$ in a network. The objective is to associate the quadratic function with resource flow and social relationship. This choice of objective function is justified by the characteristics of a super network.

The constraint set (2) controls the extent of resource transportation limited by road capacity. The constraint set (3) ensures that the total amount of resources delivered to demand point $k$ should meet the requirements. The constraint set (4) implements the conservation of the types of relief materials. The constraint set (5) imposes non-negativity. 
However, when the emergency is serious and the proposed model cannot find a solution, the small-scale emergency scheduling mode will be transformed to a large-scale mode. That is, more points will join the scheduling network and provide relief resources directly to demand points or by transit through transfer points. The objective is to minimize the total cost and to include the sum of the costs of the three parts, which is denoted as follows:

$\min \sum_{i} \sum_{j} \sum_{h} g_{i j h}\left(q_{i j h}, r_{i j}\right)+\sum_{j} \sum_{k} \sum_{h} g_{j k h}\left(q_{j k h}, r_{j k}\right)+\sum_{i} \sum_{k} \sum_{h} g_{i k h}\left(q_{i k h}, r_{i k}\right)$

(6)

This is subject to the following sets of constraints:

$\sum_{h} q_{j k h} \leq u_{j k}, \sum_{h} q_{i j h} \leq u_{i j}, \sum_{h} q_{i k h} \leq u_{i k}$, for all $h \in H, i \in I, j \in J, k \in K$

$A_{i h} \geq \sum_{j} q_{i j h}+\sum_{k} q_{i k h}$, for all $h \in H, i \in I, j \in J, k \in K$

$\sum_{i} q_{i j h} \geq \delta_{2}\left(\sum_{k} q_{j k h}-A_{j h}\right)$, for all $h \in H, i \in I, j \in J, k \in K$

$\sum_{i} q_{i k h}+\sum_{j} q_{j k h} \geq \delta_{1}\left(d_{k h}-\rho A_{k h}\right)$, for all $h \in H, i \in I, j \in J, k \in K$

$\sum_{h} q_{j k h}=q_{j k}, \sum_{h} q_{i j h}=q_{i j}, \sum_{h} q_{i k h}=q_{i k}$, for all $h \in H, i \in I, j \in J, k \in K$

$q_{i k h} \geq 0, \quad q_{i j h} \geq 0, \quad q_{j k h} \geq 0, \quad A_{i h} \geq 0, \quad A_{j h} \geq 0, \quad A_{k h} \geq 0, \quad \forall j \in J, \forall k \in K$

The objective function (6) is added directly and indirectly to the scheduling process: the cost of transporting resources from $i$ to $j$ and to demand point $k$. The structure of the objective function is quadratic. The constraint set (7) controls resource transportation quantity, which is limited by road capacity. The constraint set (8) controls resource delivery to $j$ and $k$, which is limited by the resources stored at $i$. The constraint set (9) indicates that the source of relief supplies delivered by $j$ should exceed its thresholds, including its own reserves $A_{j}$ and that transported by $i$. The constraint set (10) ensures that the total amount of resources delivered to demand point $k$ should satisfy its demand. Similarly, the constraint set (11) implements the conservation of the types of relief supplies, and the constraint set (12) imposes non-negativity.

The uncertainty of demand is expressed as a triangular fuzzy function shown in set (13).

$$
d_{k h}=\frac{d_{k h}^{1}+2 d_{k h}^{2}+d_{k h}^{3}}{4}
$$

As mentioned earlier, the emergency resource scheduling of CIPs for large emergencies exhibits an evident interrelationship among the emergency subjects in the entire scheduling 
network, which is denoted as $r_{a b}$ in this model. In general, the distance between emergency subjects is inversely proportional to the amount of resource scheduling, whereas the similarity of reserved resources among subjects is positively related to scheduling quantity. Assume that the weight of the distance is $w$ in the 'relationship'. Thus, the relationships among points are shown in Formula (14).

$$
r_{i j}=w\left(1 / d_{i j}\right)+(1-w) s_{i j}, w \in[0,1]
$$

\section{Solution approach}

\subsection{Variational inequality problem}

The model constructed above is a convex optimization problem with objective function continuity, and the convex optimization problem has the equivalent conversion relation to the variational inequality problem (VIP). VIP is regarded as an important tool for studying super-networks (Nagurney and Dong, 2002; Raciti, 2004), so the above-mentioned convex optimization model is transformed into equivalent VIP to solve.

Assuming that there is a point $X^{*} \in K$ to meet:

$$
\min f(X)
$$

Then it holds that $X^{*}$ is a solution of VI

$$
X \in K:\left\langle\nabla F\left(X^{*}\right), X-X^{*}\right) \geq 0, \forall X \in K
$$

where $\nabla F\left(X^{*}\right)$ denotes the gradient of $F(\bullet)$ to the respective components of $X$, i.e.,

$$
\nabla F\left(X^{*}\right)^{T}=\left(\frac{\partial F\left(X^{*}\right)}{\partial X_{1}}, \ldots, \frac{\partial F\left(X^{*}\right)}{\partial X_{N}}\right)
$$

Convert the established small-scale model, we obtain

$$
\begin{aligned}
& \sum_{j} \sum_{k} \sum_{h}\left[\frac{\partial g_{j k}\left(q_{j k h}, r_{j k}\right)}{\partial q_{j k h}}+\alpha_{j k}^{*}-\beta_{k}^{*}\right] \times\left[q_{i j h}-q_{i j h}^{*}\right] \\
+ & \sum_{j} \sum_{k}\left[u_{j k}-\sum_{h} q_{j k h}\right] \times\left[\alpha_{j k}-\alpha_{j k}^{*}\right] \\
+ & \sum_{k}\left[\sum_{j} q_{j k h}-\delta_{1}\left(d_{k h}+\rho A_{k h}\right)\right] \times\left[\beta_{k}-\beta_{k}^{*}\right] \\
\geq & 0
\end{aligned}
$$

where, $K=\left\{\left(q_{j k h}, \alpha_{j k}, \beta_{k}\right) \mid q_{j k h} \geq 0, \forall j, k\right\}$

and satisfy $K=\left\{\left(q_{j k h}, \alpha_{j k}, \beta_{k}\right) \mid u_{1}>q_{j k h} \geq 0 ; \alpha_{j k} \geq 0, u_{3} \geq \beta_{k} \geq 0\right\}$ 


$$
\sum_{i} \sum_{k} \sum_{h}\left[\frac{\partial g_{i k}\left(q_{i k h}, r_{i k}\right)}{\partial q_{i k h}}+\psi_{i k}^{*}-\beta_{k}^{*}-\theta_{i}^{*}\right] \times\left[q_{i k h}-q_{i k h}^{*}\right]
$$

$$
+\sum_{i} \sum_{j} \sum_{h}\left[\frac{\partial g_{i j}\left(q_{i j h}, r_{i j}\right)}{\partial q_{i j h}}+\lambda_{i j}^{*}-\gamma_{j}^{*}\right] \times\left[q_{i j h}-q_{i j h}^{*}\right]
$$

$$
+\sum_{j} \sum_{k} \sum_{h}\left[\frac{\partial g_{j k}\left(q_{j k h}, r_{j k}\right)}{\partial q_{j k h}}+\alpha_{j k}^{*}-\beta_{k}^{*}-\gamma_{j}^{*}\right] \times\left[q_{i j h}-q_{i j h}^{*}\right]
$$$$
+\sum_{i} \sum_{j}\left[u_{i j}-\sum_{h} q_{i j h}\right] \times\left[\lambda_{i j}-\lambda_{i j}^{*}\right]+\sum_{j} \sum_{k}\left[u_{j k}-\sum_{h} q_{j k h}\right] \times\left[\alpha_{j k}-\alpha_{j k}^{*}\right]
$$$$
+\sum_{i} \sum_{k}\left[u_{i k}-\sum_{h} q_{i k h}\right] \times\left[\psi_{i k}-\psi_{i k}^{*}\right]+\sum_{j}\left[\sum_{i} q_{i j h}-\delta_{2}\left(\sum_{k} q_{j k h}-A_{j h}\right)\right] \times\left[\gamma_{j}-\gamma_{j}^{*}\right]
$$$$
+\sum_{k}\left[\sum_{j} q_{j k h}+\sum_{i} q_{i k h}-\delta_{1}\left(d_{k h}+\rho A_{k h}\right)\right] \times\left[\beta_{k}-\beta_{k}^{*}\right]
$$$$
+\sum_{i}\left[A_{i h}-\sum_{j} q_{i j h}-\sum_{k} q_{i k h}\right] \times\left[\theta_{i}-\theta_{i}^{*}\right]
$$

$\geq 0$

where, $K=\left\{\left(q_{i j h}, q_{j k h}, q_{i k h}, \lambda_{i j}, \alpha_{j k}, \psi_{i k}, \beta_{k}, \gamma_{j}, \theta_{i}\right) \mid q_{i j h}, q_{j k h}, q_{i k h} \geq 0, \forall i, j, k\right\}$

and satisfy

$$
K=\left\{\left(q_{i j h}, q_{j k h}, q_{i k h}, \lambda_{i j}, \alpha_{j k}, \psi_{i k}, \beta_{k}, \gamma_{j}, \theta_{i}\right) \mid u_{1}>q_{i j h}, q_{j k h}, q_{i k h} \geq 0, u_{2} \geq \lambda_{i j}, \alpha_{j k}, \psi_{i k} \geq 0, u_{3} \geq \beta_{k}, \gamma_{j}, \theta_{i} \geq 0\right\}
$$

, where $\left\{u_{1}, u_{2}, u_{3}\right\}$ are constants, so $F(X)$ in the $\operatorname{VIP}(F, K)$ is a convex function, monotonic and continuous can be guided. It can also prove that the second derivative is bounded, according to the differential mean theorem, that there is a Lipschitz constant $L \geq 0$,make it:

$$
\left\|F\left(X_{1}\right)-F\left(X_{2}\right)\right\| \leq L\left\|X_{1}-X_{2}\right\|, \forall X_{1}, X_{2} \in K
$$

When the VIP is monotonic and Lipschitz continuous, then the solution of VIP exists and is unique.

\subsection{Modified projection algorithm}

The modified projection algorithm is a new algorithm based on the projection algorithm, which is more rapid to find the solution and more closely compared with the projection algorithm logic. Algorithm is described as follows:

$$
X^{T}=P_{K}\left(X^{T-1}-\varpi F\left(\bar{X}^{T-1}\right)\right)
$$


where $\bar{X}^{T-1}=P_{K}\left(X^{T-1}-\varpi F\left(X^{T-1}\right)\right), \varpi \in(0,1 / L], L$ is a Lipschitz constant. The specific iteration steps are as follows:

STEP 1: Initialize. Assume that $X_{0}=\left(q_{i j h}^{0}, q_{j k h}^{0}, q_{i k h}^{0}, \lambda_{i j}^{0}, \alpha_{j k}^{0}, \psi_{i k}^{0}, \beta_{k}^{0}, \gamma_{j}^{0}, \theta_{j}^{0}\right) \in K, 0 \leq \varpi \leq 1 / L$.

STEP 2: Iteration. Suppose that $\bar{X}^{T}=\left(\bar{q}_{i j h}^{t}, \bar{q}_{j k h}^{t}, \bar{q}_{i k h}^{t}, \bar{\lambda}_{i j}^{t}, \bar{\alpha}_{j k}, \bar{\psi}_{i k}^{t}, \bar{\beta}_{k}^{t}, \bar{\gamma}_{j}^{t}, \bar{\theta}_{j}^{t},\right) \in K$, find the solution of the function:

$$
\left\langle\bar{X}^{T}+\varpi F\left(X^{T-1}\right)-X^{T-1}, X-\bar{X}^{T}\right\rangle \geq 0
$$

STEP 3: Modified. Suppose that $X^{T}=\left(q_{i j h}^{t}, q_{j k h}^{t}, q_{i k h}^{t}, \lambda_{i j}^{t}, \alpha_{j k}^{t}, \psi_{i k}^{t}, \beta_{k}^{t}, \gamma_{j}^{t}, \theta_{j}^{t},\right) \in K$ find the solution of the function:

$$
\left\langle X^{T}+\varpi F\left(\bar{X}^{T}\right)-X^{T-1}, X-X^{T}\right\rangle \geq 0
$$

STEP 4: Validation of convergence. For $\varepsilon>0$,if

$\left|q_{i j h}^{t}-q_{i j h}^{t-1}\right| \leq \varepsilon \quad ;\left|q_{j k h}^{t}-q_{j k h}^{t-1}\right| \leq \varepsilon \quad ;\left|q_{i k h}^{t}-q_{i k h}^{t-1}\right| \leq \varepsilon \quad ; \quad\left|\lambda_{i j}^{t}-\lambda_{i j}^{t-1}\right| \leq \varepsilon \quad ;\left|\alpha_{j k}^{t}-\alpha_{j k}^{t-1}\right| \leq \varepsilon \quad ;$

$\left|\beta_{k}^{t}-\beta_{k}^{t-1}\right| \leq \varepsilon ;\left|\gamma_{j}^{t}-\gamma_{j}^{t-1}\right| \leq \varepsilon$, then stop iteration, else, let $t=t+1$, and turn to STEP 2.

\section{Result}

A specific site in the Pearl River Delta region in China is selected as the study area. This region, located in the central and southern parts of Guangdong Province, adjacent to Hong Kong and Macao, is known as China's 'South Gate'. The Pearl River Delta region includes Guangzhou, Shenzhen, and nine other cities, as shown in Fig. 4a. A statement from the 'Coordinated Development Plan for Urban Agglomeration in the Pearl River Delta (2004-2020)' indicates that the region has a total population of 42.3 million and covers a total land area of $41698 \mathrm{~km}^{2}$. Various types of highly developed CIPs are concentrated in the Pearl River Delta due to its geographic particularity. We selected 10 points, namely, 1 PRC, 2 LRCs, and 7 CIPs, as shown in Fig. 4b. To facilitate the subsequent expression, we assign a number to each depot as shown in Table 1. The pentagram represents the PRC, which is located in Guangzhou; the diamond represents the LRCs in Foshan and Guangzhou; and the other 7 triangles represent the CIPs. The cost function in this section is set in the following form:

$$
g\left(q_{i j h}, r_{i j}\right)=\left(10-r_{i j}\right) q^{2} i j 1+\left(6-r_{i j}\right) q_{i j 2}^{2}-r_{i j} q_{i j 1} q_{i j 2} .
$$

The required simulation data are standardized to facilitate calculation. The relationship and road capacity among the points are shown in Tables $2 \mathrm{a}$ and $2 \mathrm{~b}$, respectively.

\section{$<$ Insert Fig.4 here>}


<Insert Table 1 here>

<Insert Table 2 here>

In the model proposed in this work, different scales of disasters will require different rescue points; that is, implementing first stage or second stage relief system will depend on the disaster scenarios. Thus, in the simulation experiment presented in this section, two cases are presented for testing. Case 1 is small-scale emergency, in which resource demand is lower than that in Case 2, which is a large-scale disaster. Unlike in a general emergency scheduling situation, all points have reserves involved in the network under the context of a CIP emergency. The relief resources are assumed to be divided into two categories: daily necessities and professional supplies. Table 3 presents the two types of resources saved in each point. The data shown in Table 4 include the demand for resources of the two cases in affected CIPs (assuming that points 5,6 , and 7 suffered from an emergency).

<Insert Table 3 here>

$<$ Insert Table 4 here>

We apply the variational inequality of the modified projection algorithm proposed in Section 4 and use MATLAB to solve the scheduling problem. In Case 1, the affected CIPs (demand points) and closely related points can satisfy the demand and the flow of shipped resources are relatively small; hence, only a few rescue points participate in the relief network. The calculation result is presented in Table 5. In Case 2, however, a large-scale emergency occurs and considerable demands have to be met. The situation becomes more complicated due to the coordination and interaction among emergency subjects. The first-echelon and second-echelon scheduling results are presented in Table $6 \mathrm{a}$ and Table $6 \mathrm{~b}$, respectively.

<Insert Table 5 here>

$<$ Insert Table 6 here>

The difference in disaster scale causes a significant variation between selected suppliers and flow of rescue resources. In Case 1, the resources required by demand points are minimal, and thus, some subjects do not participate in the network. In Case 2, however, the PRC, LRCs, and all unaffected CIPs within a region become members of the relief network to contribute to emergency scheduling work (see Table $6 a$ and Table $6 \mathrm{~b}$ ).

We consider the relationship among emergency subjects in the proposed super network. Thus, making a thorough inquiry 'relationship' work to affect the scheduling process will be interesting. To this end, we observe changes in resource flow and total cost by changing the relationship of a specific path under a disaster scenario. Fig. 5-7 present each path in the super network and depict the trends of flow and total cost with an increase in path relationship. For Depot 1 (CIP located in Zhaoqing), when its relationship with an affected depot increases, the flow of delivered resources also increases, whereas total cost decreases. For Depot 8(Foshan), when the relationship of Path 8-7 (Foshan to Jiangmen) increases, the total cost 
decreases significantly faster than those of Paths 8-5 and 8-6. For Depot 9 (Guangzhou), when the relationships among Paths 9-5, 9-6, and 9-7 are strengthened, the total cost surprisingly increases and the transferred resources also increases.

\section{<Insert Fig. 5-7 here>}

From the simulation results, we can determine the key paths in the network that contribute to improve rescue effectiveness for practical applications. The development of the relationship between Depot 9 (LRC located in Guangzhou) and other CIPs will increase cost, thereby implying that Depot 9 is unsuitable for delivering supplies to demand points, at least for Depots 5, 6, and 7. By contrast, for Shenzhen (Depot 4), strengthening its relationship with Depot 7 (Jiangmen) will significantly decrease cost. These results may enlighten managers to adjust their strategies and optimize external relationships with others to achieve the global optimum.

Moreover, we discuss four location cases (all RCs in the network; no PRC in the network; no LRC; and no PRC, no LRC, and no RC), as shown in Fig. 8. The total cost decreases with an increase in retained resources. Evidently, the case without an RC participating in a super network has a considerably higher cost than the other cases.

$<$ Insert Fig. 8 here>

\section{Discussion}

The main contribution of this work is to propose a new mathematical programming approach for the selection of a supply portfolio in a relief supply chain by considering heterogeneity and relationships among CIPs. The well-established resources allocation and scheduling models in post-disaster relief management need to be revised for concentrated CIPs areas. In this work, we build a super network model for supporting emergency logistics operations in response to large regional natural hazards or chemical accidents. The proposed method primarily involves two-stage model and adapts flexibly to different disaster scenarios. A relief system associated with rescue points is automatically selected by identifying the degree of disaster and the amounts of resources required.

A lack of coordination among relief agents has been shown to increase inventory costs, extend delivery times, and impair customer service (Simatupang et al., 2002). The proposed super-network model of emergency dispatching for CIPs helps the identification of key nodes and edges in an emergency network, which provide a scientific basis for cooperation among CIPs to make emergency scheduling better in responding to cross-regional disasters. In specific applications, by simulating all kinds of disaster events, CIPs can make an optimal emergency logistics planning (optimal types and quantities of resources and optimal distribution route) that improve the relief efficacy.

For emergency relief management, indeed, relief agents often fail to make the effort, or simply find it too difficult to collaborate (Fenton, 2003), but for CIPs, they are all potential 
affected areas, a matter of course, they have incentive and willing to collaborate with each other, and may only pay a relatively small cost. The criticality of coordination of resource and information flows within and across chain members has been widely addressed in the commercial supply chain (Lee, 2000), but this mechanism is not feasible for emergency logistics (Balcik et al., 2010). Established flow-relationship super network in this paper can be a creative method benefits from commercial practices because of considering stakeholders' relationship, which allow CIPs reserve different and partial resources but get sufficient relief supplies when suffered a disaster. Joint configuration of resources can not only increase utilization of rescue equipment but also reduce costs. Therefore, the proposed method is expected not only to aid the design of a suitable emergency scheduling supply network but also to provide recommendations on resource allocation and the establishment of relationships within a network.

Considerable potential exists to improve the performance of the proposed method. First, the settings of the objective function are worthy of further research. Relief goal should consider other performance indexes, such as transportation time, which is important in emergency scheduling because of the urgency of rescue in CIPs. Second, the quantification of the social relationship is also worth exploring. On the one hand, if the rescue points are selected through the shortest path, which may make the resource traffic beyond the capacity limit caused by congestion, then the actual geographic distance increases. On the other hand, a high similarity of reserved resources is not a good relationship for some required special supplies. Future research can discuss different relationship among CIPs with various types of resources. Finally, another potential area for future research deals with the issue of scalability. We are aware of the limitations of our approach in terms of applying the super network model and its solution procedure to actual-sized case studies, basically because the solution for variational inequality will be more complex as it grows exponentially in size with respect to the number of agents involved in the system. The answers to such questions will contribute importantly to emergency scheduling management in the future.

\section{Declaration of Interest Statement}

The authors declare that they have no known competing financial interests or personal relationships that could have appeared to influence the work reported in this paper.

\section{Ethical Approval}

Not applicable.

\section{Consent to Participate}

Not applicable.

\section{Consent to Publish}

Not applicable.

\section{Authors Contributions}


Yu Yuan developed the theoretical formalism, performed the analytic calculations and performed the numerical simulations. Fei Wang supervised the project and was a major contributor in writing the manuscript. All authors read and approved the final manuscript.

\section{Funding}

The writing of this article was supported by National key R \& D projects,

\section{YFC0801505.}

\section{Competing Interests}

The authors declare no competing interests.

\section{Availability of data and materials}

The data that support the findings of this study are available from the corresponding author upon reasonable request.

\section{References}

Al-qurashi, F ( 2004) New vision of emergency response planning. Process Safety Progress, 23(1), $56-61$.

Balcik, B., Beamon, B. M., Krejci, C. C., Muramatsu, K. M., \& Ramirez, M (2010) Coordination in humanitarian relief chains: Practices, challenges and opportunities. International Journal of Production Economics, 126(1), 22-34.

Baser, B., \& Behnam, B. (2020). An emergency response plan for cascading post-earthquake fires in fuel storage facilities. Journal of Loss Prevention in the Process Industries, 65, 104155.

Bell J E, Griffis S E, Cunningham III W A, et al (2011) Location optimization of strategic alert sites for homeland defense. Omega, 39(2): 151-158.

Chang M S, Tseng Y L, Chen J W (2007) A scenario planning approach for the flood emergency logistics preparation problem under uncertainty. Transportation Research Part E: Logistics and Transportation Review, 43(6): 737-754.

Chen, Y., Zhao, Q., Wang, L., \& Dessouky, M (2016) The regional cooperation-based warehouse location problem for relief supplies. Computers \& Industrial Engineering, 102, 259-267.

Cruz, J. M., \& Liu, Z (2011) Modeling and analysis of the multiperiod effects of social relationship on supply chain networks. European Journal of Operational Research, 214(1), $39-52$.

Daskin, M. S (1985) Urban transportation networks: Equilibrium analysis with mathematical programming methods. 463-466.

Du, Y., Sun, J., Duan, Q., Qi, K., Xiao, H., \& Liew, K. M. (2020). Optimal Assignments of Allocating and Scheduling Emergency Resources to Accidents in Chemical Industrial Parks. Journal of Loss Prevention in the Process Industries, 65, 104148.

Du, Y., Xiao, H., Sun, J., Duan, Q., Qi, K., Chai, H., \& Liew, K. M. (2020). Hierarchical pre-positioning of emergency resources for a chemical industrial parks concentrated area. Journal of Loss Prevention in the Process Industries, 66, 104130. 
Duan W, He B (2015) Emergency response system for pollution accidents in chemical industrial parks, China. International journal of environmental research and public health, 12(7): 7868-7885.

Fan, B (2014) Hybrid spatial data mining methods for site selection of emergency response centers. Natural hazards, 70(1), 643-656.

Feng, J. R., Gai, W. M., Li, J. Y., \& Xu, M. (2020). Location selection of emergency supplies repositories for emergency logistics management: A variable weighted algorithm. Journal of Loss Prevention in the Process Industries, 63, 104032.

Fiedrich, F., Gehbauer, F., \& Rickers, U (2000) Optimized resource allocation for emergency response after earthquake disasters. Safety science, 35(1), 41-57.

Fitzsimmons, J. A (1973) A methodology for emergency ambulance deployment. Management Science, 19(6), 627-636.

Fu, Y., \& Piplani, R (2004) Supply-side collaboration and its value in supply chains. European Journal of Operational Research, 152(1), 281-288.

Georgiadou, P. S., Papazoglou, I. A., Kiranoudis, C. T., \& Markatos, N. C (2010) Multi-objective evolutionary emergency response optimization for major accidents. Journal of hazardous materials, 178(1), 792-803.

Green, L. V., \& Kolesar, P. J (2004) Anniversary article: Improving emergency responsiveness with management science. Management Science, 50(8), 1001-1014.

Groothedde, B., Ruijgrok, C., \& Tavasszy, L (2005) Towards collaborative, intermodal hub networks: A case study in the fast moving consumer goods market. Transportation Research Part E: Logistics and Transportation Review, 41(6), 567-583.

Hackl, F., \& Pruckner, G. J (2006) Demand and supply of emergency help: An economic analysis of Red Cross services. Health Policy, 77(3), 326-338.

Hedemann-Jensen, P (2004) Protective actions in the late phase-intervention criteria and decision-making. Radiation protection dosimetry, 109(1-2), 45-51.

Horner M W, Downs J A (2010) Optimizing hurricane disaster relief goods distribution: model development and application with respect to planning strategies. Disasters, 34(3): 821-844.

Houming, F., Tong, Z., Xiaoyan, Z., Mingbao, J., \& Guosong, D (2008) Research on emergency relief goods distribution after regional natural disaster occurring. InInformation Management, Innovation Management and Industrial Engineering, 2008. ICIII'08. International Conference on (Vol. 3, pp. 156-161). IEEE.

Jia, H., Ordóñez, F., \& Dessouky, M. M (2007) Solution approaches for facility location of medical supplies for large-scale emergencies. Computers \& Industrial Engineering,52(2), 257-276. 
Kapucu, N., Arslan, T., \& Collins, M. L (2010) Examining intergovernmental and inter-organizational response to catastrophic disasters: Toward a networkcentered approach. Administration \& Society, 42(2), 222-247.

Khan F I, Abbasi S A (2001) An assessment of the likelihood of occurrence, and the damage potential of domino effect (chain of accidents) in a typical cluster of industries[J]. Journal of Loss Prevention in the Process Industries, 14(4): 283-306.

Kourniotis, S. P., Kiranoudis, C. T., \& Markatos, N. C (2001) A systemic approach to effective chemical emergency management. Safety science, 38(1), 49-61.

Lee, H. L (2000) Creating value through supply chain integration. Supply chain management review, 4(4), 30-36.

Liu J, Guo L, Jiang J, et al (2017) Emergency material allocation and scheduling for the application to chemical contingency spills under multiple scenarios. Environmental Science and Pollution Research, 24(1): 956-968.

Maliszewski P J, Kuby M J, Horner M W (2012) A comparison of multi-objective spatial dispersion models for managing critical assets in urban areas. Computers, Environment and Urban Systems, 36(4): 331-341.

Nagurney, A., Cruz, J., \& Wakolbinger, T (2007) The co-evolution and emergence of integrated international financial networks and social networks: Theory, analysis, and computations. Globalization and Regional Economic Modeling, 183-226.

Nagurney, A., Dong, J., \& Zhang, D (2002) A supply chain network equilibrium model. Transportation Research Part E: Logistics and Transportation Review, 38(5), 281-303.

Paul, J. A., \& Batta, R (2008) Models for hospital location and capacity allocation for an area prone to natural disasters. International Journal of Operational Research, 3(5), 473-496.

Raciti, F (2004) Equilibria trajectories as stationary solutions of infinite-dimensional projected dynamical systems. Applied Mathematics Letters, 17(2), 153-158.

Reniers, G. L. L., Dullaert, W., Ale, B. J. M., \& Soudan, K (2005) Developing an external domino accident prevention framework: Hazwim. Journal of Loss Prevention in the process industries, 18(3), 127-138.

Rogers, G. O., Watson, A. P., Sorensen, J. H., Sharp, R. D., \& Carnes, S. A (1990) Evaluating protective actions for chemical agent emergencies. ORNL-6615, Oak Ridge National Laboratory, Oak Ridge, Tenn.

Sheu, J. B (2007) An emergency logistics distribution approach for quick response to urgent relief demand in disasters. Transportation Research Part E: Logistics and Transportation Review, 43(6), 687-709.

Tsai, Y., Wang, Z., \& Yang, C. T (2002) A prototype real-time GPS/GIS-based emergency response system for locating and dispatching moving patrol vehicles with the beat-based shortest distance search. In Traffic And Transportation Studies. pp. 1361-1368. 
Wex F, Schryen G, Feuerriegel S, et al (2014) Emergency response in natural disaster management: Allocation and scheduling of rescue units. European Journal of Operational Research, 235(3): 697-708.

Yamada, T., Imai, K., Nakamura, T., \& Taniguchi, E (2011) A supply chain-transport supernetwork equilibrium model with the behaviour of freight carriers. Transportation Research Part E: Logistics and Transportation Review, 47(6), 887-907.

Zhang J H, Li J, Liu Z P (2012) Multiple-resource and multiple-depot emergency response problem considering secondary disasters. Expert Systems with Applications, 39(12): 11066-11071.

Zhao, L., Zhang, H., \& Wu, W. (2017). Knowledge service decision making in business incubators based on the supernetwork model. Physica A: Statistical Mechanics and its Applications, 479, 249-264.

Zhou, Y., \& Liu, M (2012) Risk assessment of major hazards and its application in urban planning: A case study. Risk analysis,32(3), 566-577.

Zhu, L., \& Cao, J (2012) Study on emergency resources allocation under disaster: A supernetwork perspective. Soft Science, 26(11), 38-42. 
Table 1 The number of emergencies entitles in the Fig.3

\begin{tabular}{cccc}
\hline number & city & number & city \\
\hline 1 & Zhaoqing (fine) & 6 & Zhongshan (integrate/fine) \\
2 & Huizhou (petroleum) & 7 & Jiangmen (fine) \\
3 & Dongguan (fine/petroleum) & 8 & Foshan (integrate) \\
5 & Shenzhen (fine) & 9 & Guangzhou (integrate) \\
\hline
\end{tabular}


Table 2a The social relationships between the emergency relief entities

\begin{tabular}{|c|c|c|c|c|c|c|c|c|c|c|}
\hline$r_{a b}$ & 1 & 2 & 3 & 4 & 5 & 6 & 7 & 8 & 9 & 10 \\
\hline 1 & -- & 10 & 7 & 7.6 & 7.4 & 6.4 & 4.7 & 6.5 & 5.3 & 6.7 \\
\hline 2 & & -- & 5.2 & 6.6 & 7.5 & 9.3 & 9.8 & 8.5 & 6.3 & 7.7 \\
\hline 3 & & & -- & 4.7 & 5.2 & 4.5 & 5.8 & 6.8 & 3.9 & 6 \\
\hline 4 & & & & -- & 6.7 & 5.8 & 5.8 & 7.8 & 5.5 & 7.7 \\
\hline 5 & & & & & -- & 3.4 & 5 & 7.3 & 5.3 & 7.4 \\
\hline 6 & & & & & & -- & 3.9 & 4.8 & 5 & 6.4 \\
\hline 7 & & & & & & & -- & 5.8 & 5 & 6.4 \\
\hline 8 & & & & & & & & -- & 4.9 & 5 \\
\hline 9 & & & & & & & & & -- & 4.3 \\
\hline 10 & & & & & & & & & & -- \\
\hline \multicolumn{11}{|c|}{ Table $\mathbf{2 b}$ The road limits between the emergency relief entities } \\
\hline$u_{a b}$ & 1 & 2 & 3 & 4 & 5 & 6 & 7 & 8 & 9 & 10 \\
\hline 1 & -- & 22 & 26 & 73 & 60 & 20 & 50 & 71 & 62 & 78 \\
\hline 2 & & -- & 28 & 46 & 62 & 53 & 66 & 20 & 60 & 82 \\
\hline 3 & & & -- & 38 & 77 & 42 & 67 & 40 & 55 & 96 \\
\hline 4 & & & & -- & 36 & 33 & 89 & 26 & 64 & 73 \\
\hline 5 & & & & & -- & 25 & 65 & 103 & 73 & 35 \\
\hline 6 & & & & & & -- & 36 & 40 & 29 & 74 \\
\hline 7 & & & & & & & -- & 52 & 48 & 41 \\
\hline 8 & & & & & & & & -- & 83 & 56 \\
\hline 9 & & & & & & & & & -- & 34 \\
\hline 10 & & & & & & & & & & -- \\
\hline
\end{tabular}


Table 3 The given data of the number of saved resources and the demand

\begin{tabular}{ccccccccccc}
\hline $\begin{array}{c}\text { Resources saved } \\
\text { in the points }\end{array}$ & 1 & 2 & 3 & 4 & 5 & 6 & 7 & 8 & 9 & 10 \\
\hline Type 1 & 80 & 50 & 20 & 100 & 40 & 58 & 30 & 35 & 20 & 100 \\
Type 2 & 45 & 50 & 20 & 50 & 20 & 0 & 30 & 20 & 30 & 60 \\
\hline
\end{tabular}


Table 4 The number of resources demand of the two cases

\begin{tabular}{ccccccccc}
\hline & retention & \multicolumn{2}{c}{5} & \multicolumn{2}{c}{6} & \multicolumn{2}{c}{7} \\
\cline { 3 - 8 } Case & factor & Type 1 & Type2 & Type 1 & Type2 & Type 1 & Type2 \\
\hline Case 1 & $\rho=0.8$ & 74 & 36 & 72 & 9 & 48 & 49 \\
Case 2 & $\rho=0.5$ & 105 & 100 & 80 & 35 & 130 & 30 \\
\hline
\end{tabular}


Table 5 Case1: the results of resource allocation in small-scale emergency

\begin{tabular}{cccccccccc}
\hline type & $q_{4,5}$ & $q_{4,6}$ & $q_{4,7}$ & $q_{8,5}$ & $q_{8,6}$ & $q_{8,7}$ & $q_{9,5}$ & $q_{9,6}$ & $q_{9,7}$ \\
\hline$h_{1}$ & 5 & 5 & 5 & 3 & 3 & 3 & 9 & 6 & 5 \\
$h_{2}$ & 13 & 10 & 11 & 6 & 5 & 4 & 7 & 6 & 5 \\
\hline sum & 18 & 15 & 16 & 9 & 8 & 8 & 16 & 12 & 10 \\
\hline
\end{tabular}


Table 6a Case 2: the first-stage results of resource allocation in large-scale emergency

$\begin{array}{lllllllllllllllll}\text { case } & \text { type } & q_{1,5} & q_{1,6} & q_{1,7} & q_{4,5} & q_{4,6} & q_{4,7} & q_{8,5} & q_{8,6} & q_{8,7} & q_{9,5} & q_{9,6} & q_{9,7} & q_{10,5} & q_{10,6} & q_{10,7}\end{array}$ $\begin{array}{llllllllllllllll}h_{1} & 38 & 11 & 16 & 16 & 21 & 54 & 22 & 18 & 25 & 15 & 13 & 17 & 15 & 17 & 17\end{array}$ $\rho=0$

$\begin{array}{llllllllllllllll}h_{2} & 21 & 7 & 14 & 20 & 7 & 14 & 20 & 7 & 14 & 19 & 7 & 14 & 19 & 7 & 14\end{array}$

$\begin{array}{llllllllllllllll}\text { Sum } & 59 & 18 & 30 & 36 & 28 & 68 & 42 & 25 & 39 & 34 & 20 & 31 & 34 & 24 & 31\end{array}$

$\begin{array}{llllllllllllllll}h_{1} & 18 & 11 & 24 & 14 & 9 & 20 & 23 & 8 & 19 & 15 & 12 & 33 & 14 & 11 & 19\end{array}$

$\rho=0.5$

$\begin{array}{lllllllllllllllll}h_{2} & 19 & 7 & 8 & 13 & 6 & 23 & 30 & 5 & 5 & 14 & 9 & 15 & 13 & 7 & 5\end{array}$

$\begin{array}{llllllllllllllll}\text { Sum } & 37 & 18 & 32 & 27 & 15 & 43 & 53 & 13 & 24 & 29 & 21 & 48 & 27 & 18 & 24\end{array}$

Table 6b Case 2: the second-stage results of resource allocation in large-scale emergency

\begin{tabular}{cccccccc}
\hline Case & type & $q_{2,8}$ & $q_{2,9}$ & $q_{3,8}$ & $q_{3,9}$ & $q_{10,8}$ & $q_{10,9}$ \\
\hline$\rho=0$ & $h_{1}$ & 11 & 2 & 3 & 3 & 16 & 20 \\
& $h_{2}$ & 7 & 3 & 7 & 3 & 7 & 3 \\
\hline & Sum & 18 & 5 & 10 & 6 & 23 & 23 \\
\hline & $h_{1}$ & 6 & 6 & 5 & 7 & 7 & 10 \\
& $h_{2}$ & 5 & 3 & 3 & 4 & 6 & 5 \\
& Sum & 11 & 9 & 8 & 11 & 13 & 15 \\
\hline
\end{tabular}




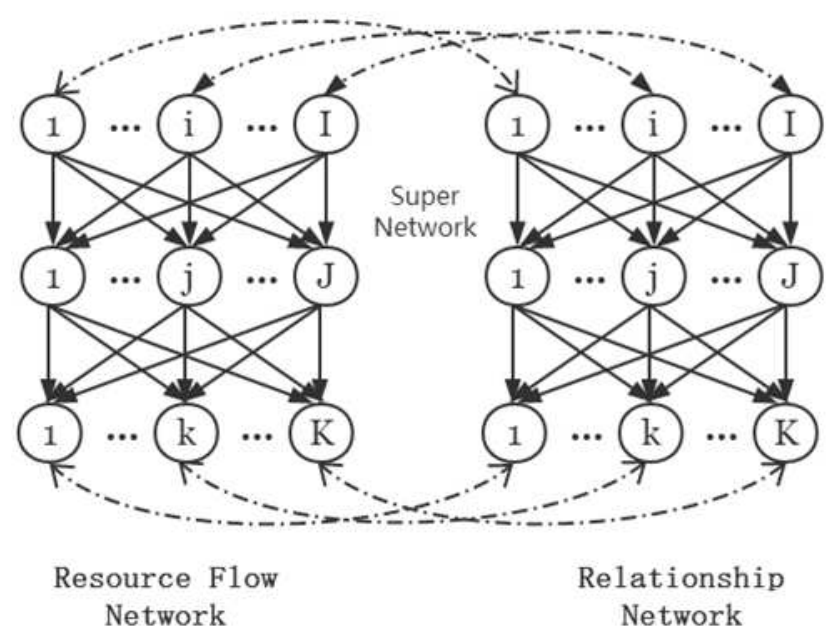

Fig.1 The concept illustration of super network involving resource flow and relationship network 


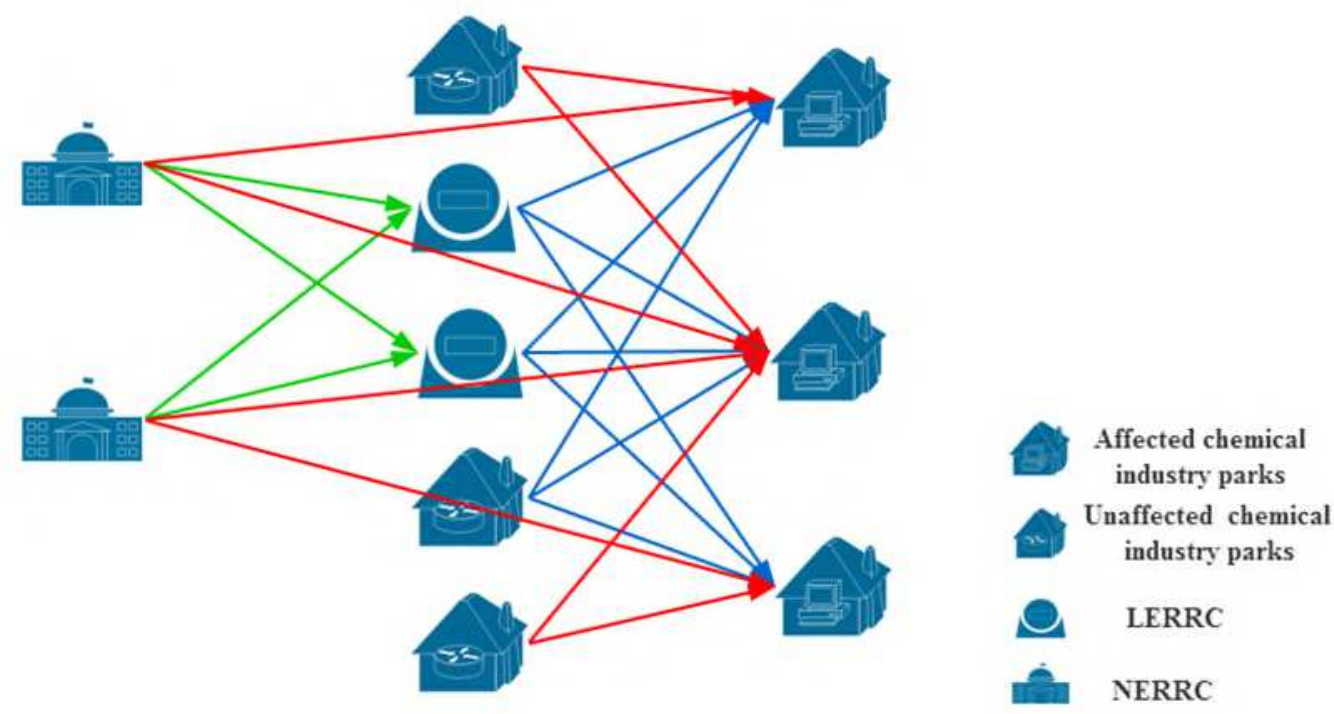

Fig.2 The conceptual model of the two-stage emergency supplying network 


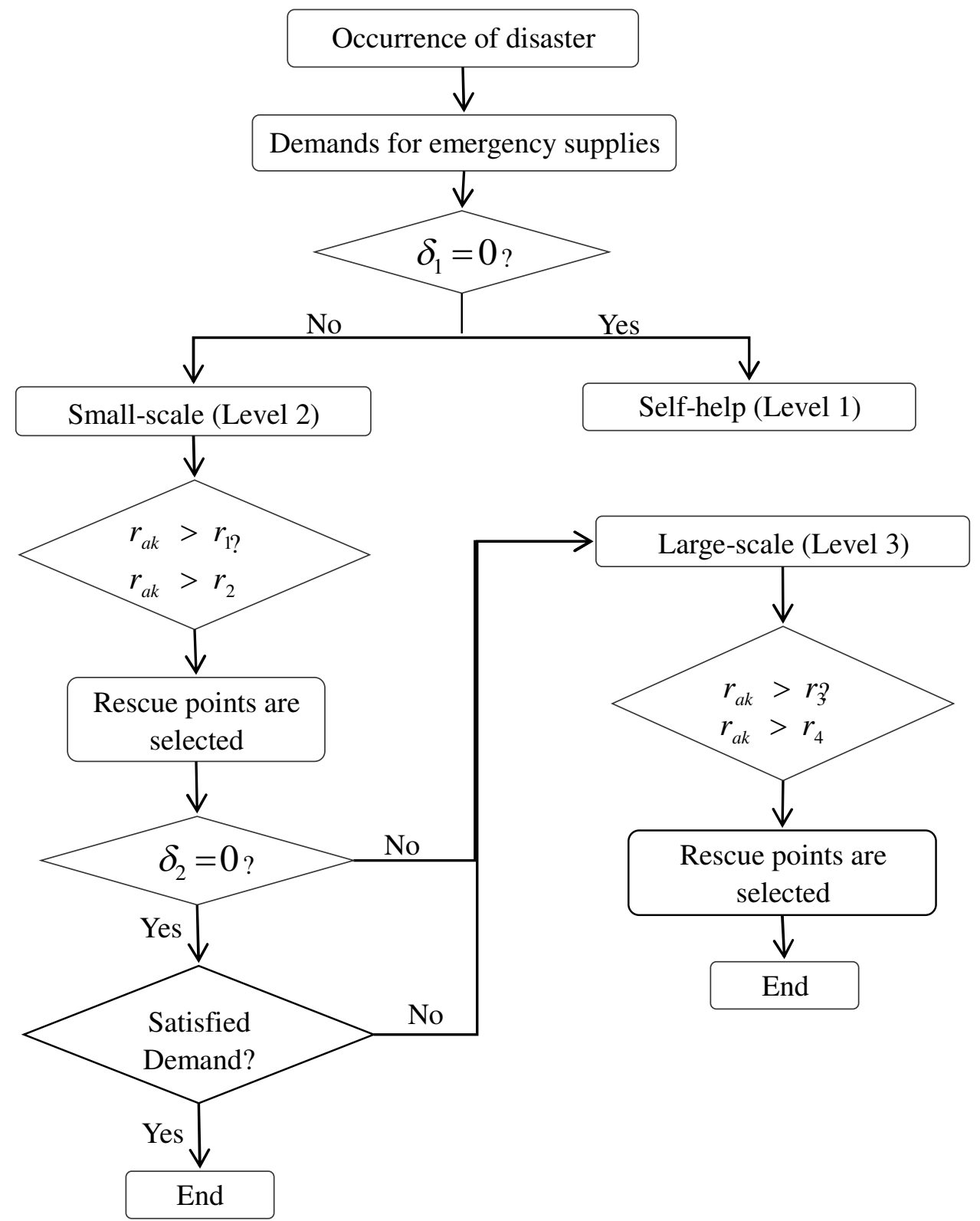

Fig.3 The decision model the relief process of this model 


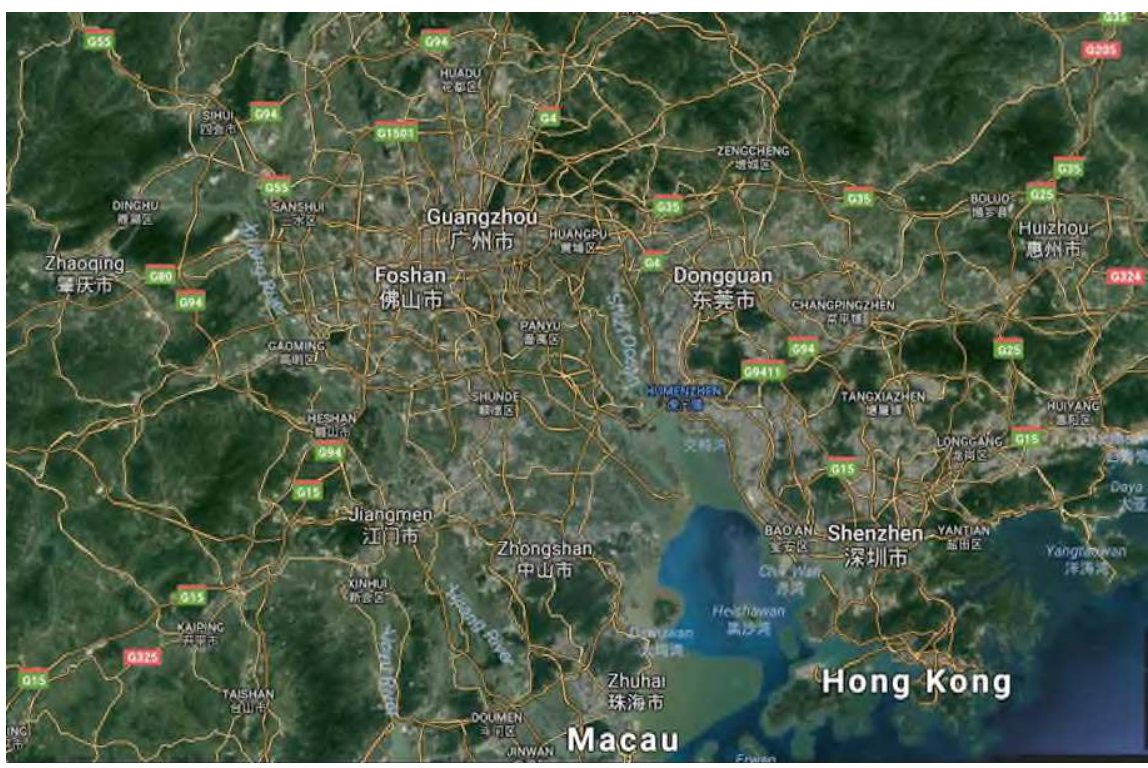

Fig.4a The map illustration of Pearl River Delta region.

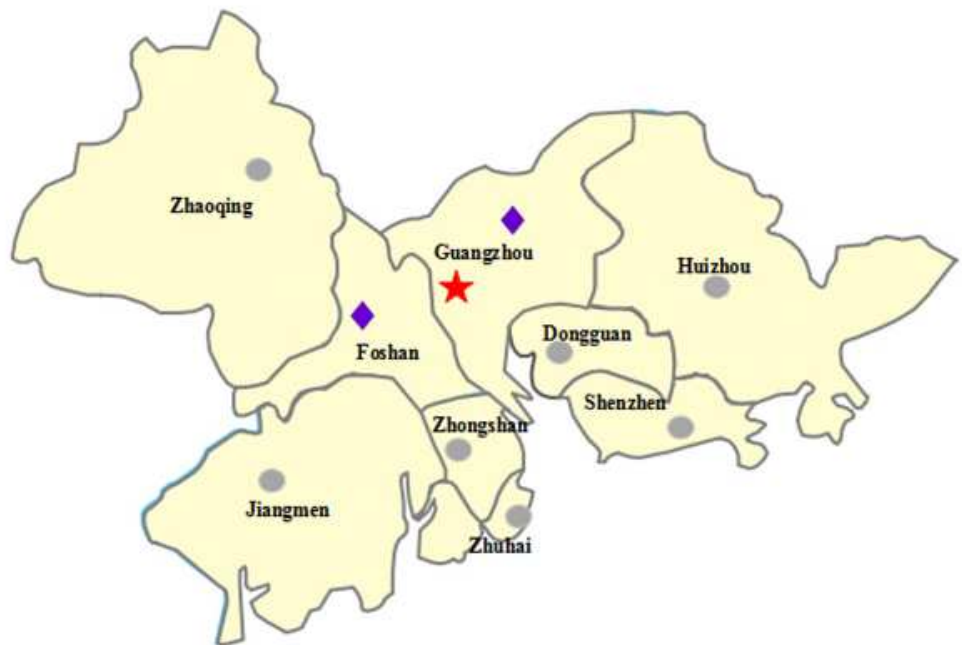

Fig.4b The distribution of emergency entities in Pearl River Delta region 
(a)

(b)

path 1-5

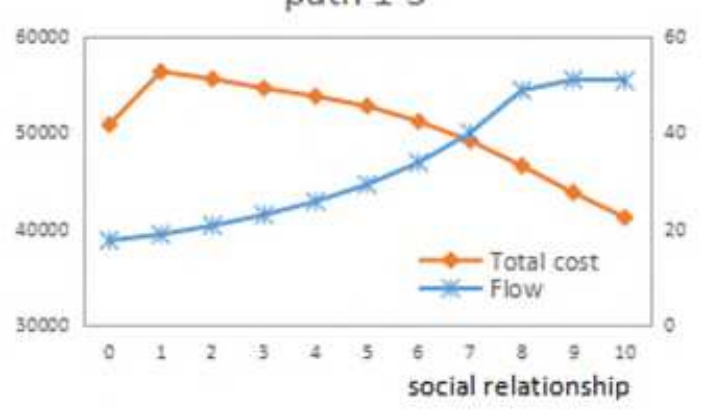

(c)

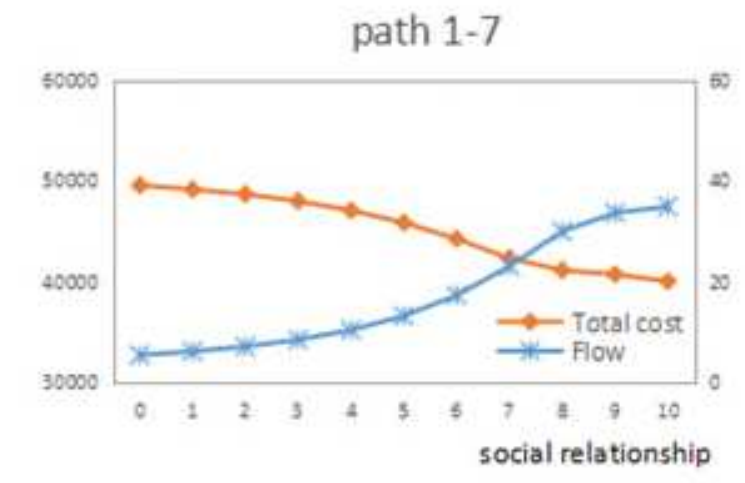

path 1-6

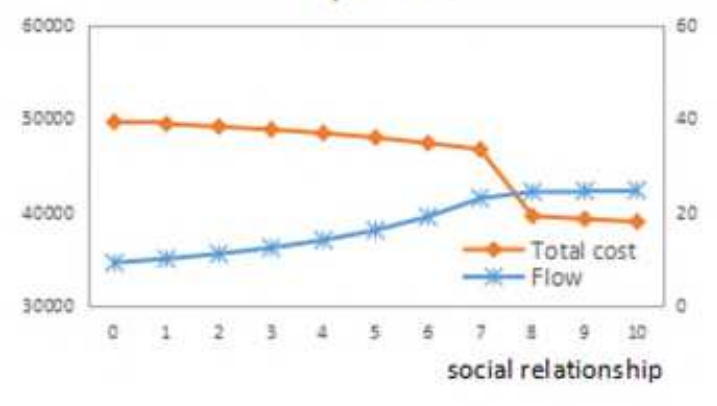

Fig.5 The flow and total cost change with social relationship between depot 1 (Zhaoqing) and demand points 
(a)

(b)
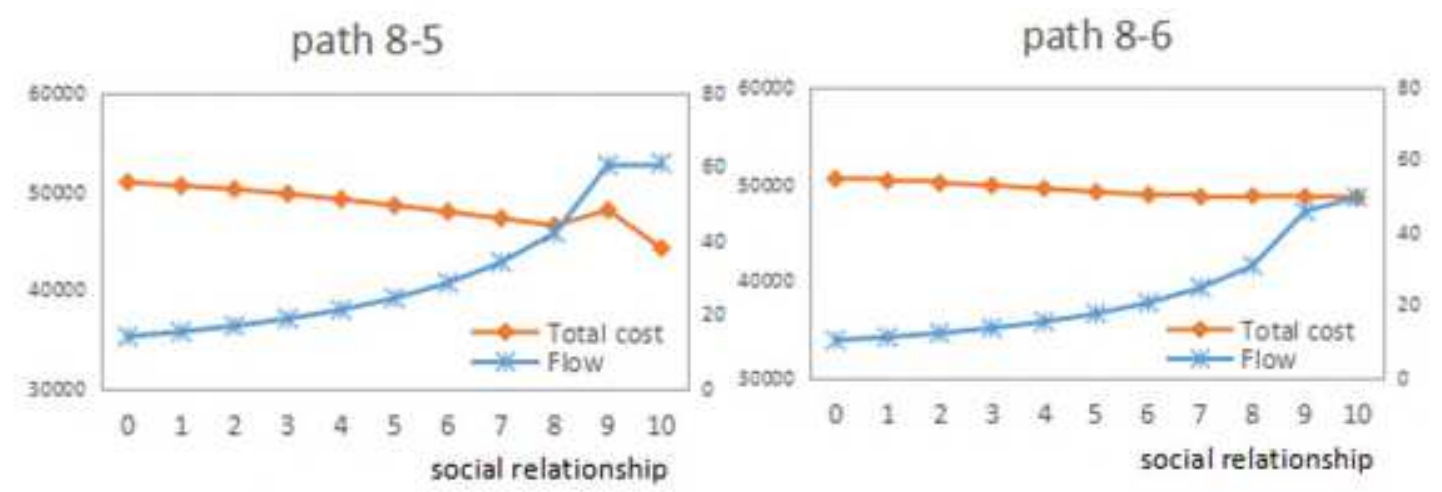

(c)

path 8-7

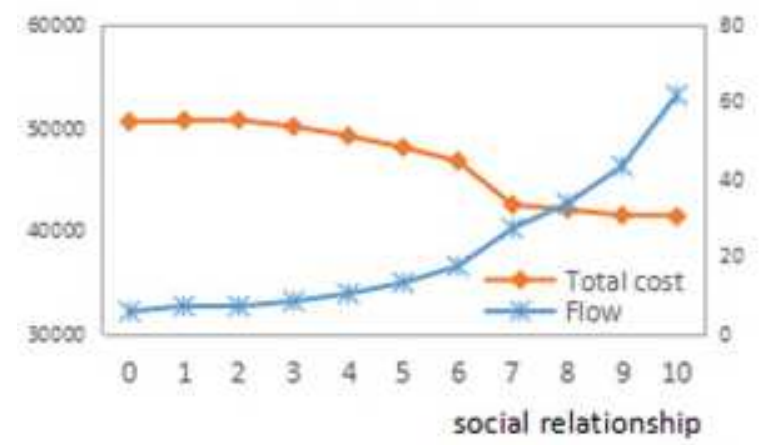

Fig.6 The flow and total cost change with social relationship between LRC 8 (Foshan) and demand points 
(a)

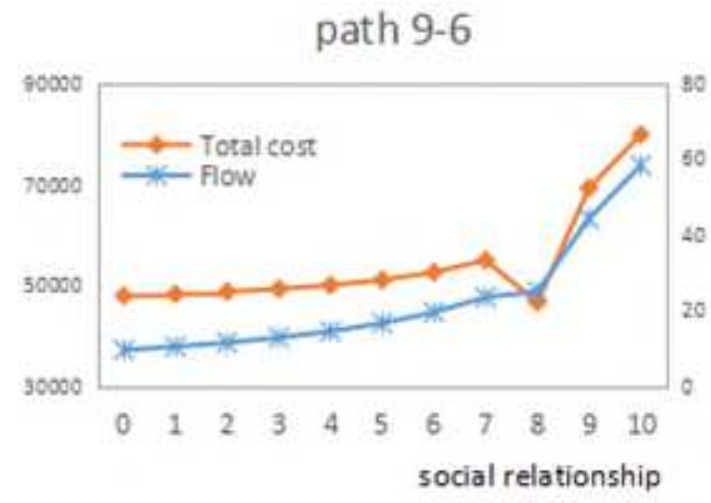

(c)

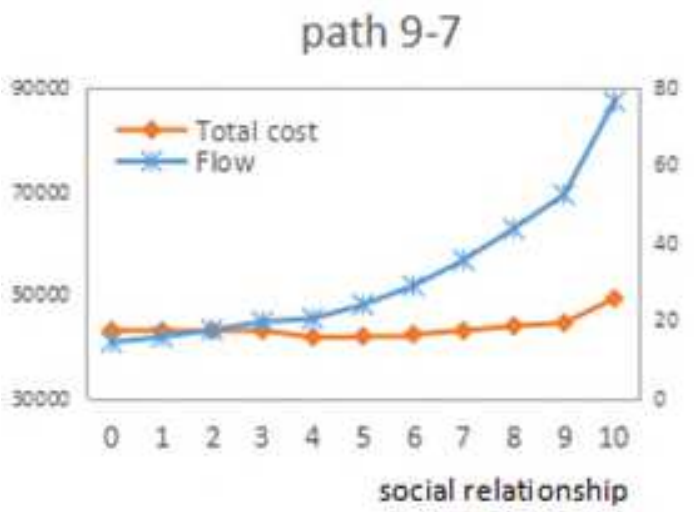

Fig.7 The flow and total cost change with social relationship between LRC 9 (Guangzhou) and demand points 


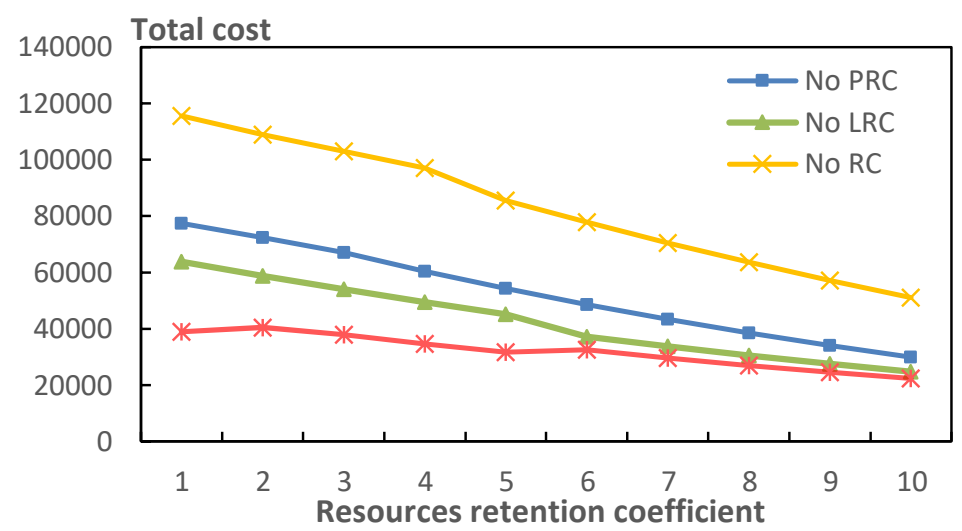

Fig.8 The total cost decreases with the resources retention coefficient increases. 